\title{
A Segurança Hídrica Domiciliar e os Serviços Ecossistêmicos na Serra de Martins - RN
}

\author{
Home Water Security and Ecosystem Services in "Serra do Martins", Rio Grande do \\ Norte State
}

\begin{abstract}
Seguridad del Agua en el Hogar y Servicios Ecosistémicos en la Sierra de Martins $R N$
\end{abstract}

\author{
Helania Pereira Silva ${ }^{1}$ \\ Jader de Oliveira Santos ${ }^{2}$
}

RESUMO: A injustiça ambiental não acontece apenas em países desfavorecidos, ela ocorre também no seio de nações desenvolvidas e em desenvolvimento, concentrada, principalmente, nas desigualdades de raça e de gênero, na apropriação de áreas indígenas, nos grupos minoritários e nas divergências pelo uso da água. Entretanto, é fato que os conflitos socioambientais são muito mais visíveis e danosos nos países mais pobres: eles não adotam uma governança integrada à conservação dos serviços ecossistêmicos, aspecto essencial para o bem-estar das populações e para o equilíbrio ecológico. Dessa forma, uma nação que busca por segurança hídrica deve assegurar as funções ecossistêmicas da natureza, lutando por justiça ambiental. Assim, o objetivo deste artigo é entender a segurança hídrica domiciliar na Serra de Martins - RN, analisando a oferta dos serviços ecossistêmicos de provisão e a justiça ambiental. Como procedimento metodológico, adotou-se: base cartográfica; campo; análise bibliográfica; visita a setores dos recursos hídricos e gestão municipal; aplicação de questionário sobre segurança hídrica domiciliar; e proposta de tratamento dos dados. Destacou-se a relação de injustiça ambiental no acesso às fontes de água subterrânea na Serra de Martins e a não segurança hídrica domiciliar, o que revela conflitos ecológicos distributivos. E, ainda, o uso infrene dos serviços ecossistêmicos de provisão, expondo ineficiência para uma governabilidade mais ecológica.

PALAVRAS-CHAVE: Segurança hídrica. Justiça ambiental. Serviços ecossistêmicos. Governança.

\begin{abstract}
Environmental injustice does not only occur in poor countries, but also in developed and developing nations, mainly regarding the inequalities of race, gender, appropriation of indigenous areas; minority groups, and conflicts over water use. However, it is a fact that socio-environmental conflicts are much more visible and harmful in poorer countries. These countries do not adopt governance integrated into the conservation of ecosystem services, which are essential for the wellbeing of the populations and ecological balance. Thereby, a nation that seeks for water security must assure the ecosystem functions of nature, fighting for environmental justice. Thus, this study aimed to

\footnotetext{
${ }^{1}$ Programa de Pós-graduação em Geografia pela Universidade Federal do Ceará-UFC. Campus do Pici, Bloco 902. CEP: 60455-760. Fortaleza-CE. E-mail: helaniageo@hotmail.com.

2 Programa de Pós-graduação em Geografia da Universidade Federal do Ceará-UFC. Campus do Pici, Bloco 902. CEP: 60455-760. Fortaleza-CE. E-mail: jader.santos@gmail.com.
} 
understand home water security in "Serra do Martins", Rio Grande do Norte State, Brazil, analyzing the supply of provision ecosystem services and the environmental justice. As a methodological procedure, the following strategies were adopted: cartographic base, field research, bibliographic analysis, visits to water resources and municipal management sectors, application of a questionnaire on home water security, and proposal for data treatment. The relationship between environmental injustice, in accessing the underground water sources in "Serra do Martins", and the lack of home water security stood out, revealing distributive ecological conflicts, in addition to an infrequent provision ecosystem services, indicating inefficiency to greener governance.

KEYWORDS: Water safety. Environmental justice. Ecosystem services. Governance.

RESUMEN: La injusticia ambiental no sólo ocurre en los países desfavorecidos, sino también en las naciones desarrolladas y en desarrollo, concentrándose principalmente en las desigualdades de raza y de género, en la apropiación de áreas indígenas, en los grupos minoritarios y en las divergencias por el uso del agua. Sin embargo, es cierto que los conflictos socioambientales son mucho más visibles y dañinos en los países más pobres: no adoptan una gobernanza integrada para la conservación de los servicios ecosistémicos, un aspecto esencial para el bienestar de las poblaciones y el equilibrio ecológico. De esta forma, una nación que busca seguridad hídrica debe asegurar las funciones ecosistémicas de la naturaleza, luchando por la justicia ambiental. Así, el objetivo de este artículo es entender la seguridad hídrica domiciliaria en la Sierra de Martins - RN, analizando la oferta de los servicios ecosistémicos de provisión y la justicia ambiental. Como procedimiento metodológico, se adoptó: base cartográfica; campo; análisis bibliográfico; visita a sectores de los recursos hídricos y gestión municipal; aplicación de cuestionario sobre seguridad hídrica domiciliar; y propuesta de tratamiento de datos. Se destacó la relación de injusticia ambiental en el acceso a las fuentes de agua subterránea en la Sierra de Martins y la no seguridad hídrica domiciliar, lo que revela conflictos ecológicos distributivos. Y, además, el uso infrene de los servicios ecosistémicos de provisión, exponiendo ineficiencia para una gobernabilidad más ecológica.

PALABRAS CLAVES: Seguridad hídrica. Justicia ambiental. Servicios ecosistémicos. Gobernabilidad.

\section{INTRODUÇÃO}

Os conflitos socioambientais são inerentes ao estilo de vida atual. A sociedade, em sua ânsia por crescimento econômico e busca por novas tecnologias, produz e consome para além da capacidade de reposição dos recursos, explorando os serviços ofertados pela natureza em grande demanda, ocasionando assim o seu esgotamento. O homem explora descontroladamente os bens naturais, conferindo uma desproporção entre o uso e a procura por novas fontes de alimentos, água, energia e produtos florestais, inserindo dessa maneira relações injustas e menos distributivas. Nesse processo, as nações pobres sofrem muito mais os impactos das relações comerciais, pois elas são espaços para a exploração de grandes empresas (transnacionais), as quais se instalam para praticar a oferta de empregos em troca de matéria-prima abundante, usufruindo de muitos outros benefícios, incluindo facilidades ambientais. 
As terras, a biodiversidade e as fontes d'água limpas são bens cobiçados pelas nações ricas, uma vez que, muitas vezes, elas não são detentoras de riqueza natural e ainda controlam a demanda internacional através de suas transnacionais. Assim, conquistam ofertas de matérias-primas, mão de obra e incentivos fiscais em nações pobres, as empenhorando através de empréstimos ou de dependência tecnológica e empregatícia, por conseguinte traçando relações injustas e desiguais na partilha dos bens naturais e dos valores culturais.

A desigual distribuição no acesso à água é um considerável exemplo desse processo. No cenário mundial, esse fenômeno atinge de modo mais intenso os países em desenvolvimento e as populações vulneráveis. Essa é a razão pela qual os conflitos ecológicos distributivos, decorrentes do uso e do acesso à água, geram demandas por justiça ambiental, as quais se voltam contra o discurso da privatização, da precificação e da excessiva mercantilização desse tão indispensável bem ambiental (RAMMÊ, 2012).

No âmbito da Ecologia Política são discutidos os movimentos por justiça ambiental. Grupos lutam pela igualdade no acesso aos bens naturais e ao meio ambiente menos poluído, bem como pelos direitos básicos das comunidades tradicionais. Isso gera lutas de classes, porque parte da população é muitas vezes fragilizada por suas condições de moradia (consequência da ausência do poder público), renegadas a territórios da "exclusão".

Desse modo, é a partir de um discurso por justiça ambiental e por uma governança mais ecológica que a temática da segurança hídrica domiciliar permeia os estudos recentes. Trata-se de um tema importante, tendo em vista seu direcionamento para o modo de distribuição e qualidade da água ofertada às comunidades, pois a má qualidade da água afeta a saúde humana e o funcionamento dos ecossistemas. Por isso, é necessário manter os padrões da qualidade da água e seu gerenciamento adequado. Cook e Bakker (2012) nos lembram de que o conceito de segurança da água surgiu na década de 1990 e evoluiu significativamente desde então. Há duas décadas, o termo estava diversamente ligado à segurança militar, à segurança alimentar e (mais raramente) à segurança ambiental. Em 2000, no Segundo Fórum Mundial, a Global Water Partnership (2000, p. 1) "introduziu uma definição integrativa de segurança da água que considerava o acesso e a acessibilidade da água, bem como as necessidades humanas e a saúde ecológica."

Destarte, esta pesquisa mostra-se relevante por trazer a discussão da segurança hídrica domiciliar numa área de "enclave úmido do sertão" (SOUZA; OLIVEIRA, 2006), envolvida em conflitos distributivos de acesso à água, mesmo sendo um ambiente natural com predisposição hídrica de suas águas subterrâneas. E esses conflitos perpassam políticas públicas e relações de poder. Temos como cerne da nossa investigação se a segurança hídrica domiciliar na serra do município de Martins - RN é garantida por sua predisposição em águas subterrâneas. Nesse sentido, o objetivo geral da pesquisa é 
entender a segurança hídrica domiciliar nessa serra, analisando a oferta dos serviços ecossistêmicos de provisão (água) e a justiça ambiental.

\section{LOCALIZAÇÃO DA ÁREA DE ESTUDO}

O município de Martins - RN abrange a Serra do Martins, constituição geológica de mesmo nome. Está situado na mesorregião do Oeste Potiguar do Estado do Rio Grande do Norte. Sua população é de 8.218 habitantes (IBGE, 2010) e sua área territorial é de 169,464 quilômetros quadrados. O município tem 27 comunidades rurais. É marcado por sua "paisagem de exceção" e riqueza hidrogeológica, fazendo parte da Formação Serra do Martins (Figuras 1 e 2). Martins tem um clima tropical, onde há muito menos pluviosidade no inverno que no verão. Segundo a classificação Köppen-Geiger, o clima é Aw, $22.7^{\circ} \mathrm{C}$ é a temperatura média e 1.127 milímetros é a pluviosidade média anual.

Figura 1 - Chapadão da Serra do Martins e Depressão Sertaneja abaixo (A e B)

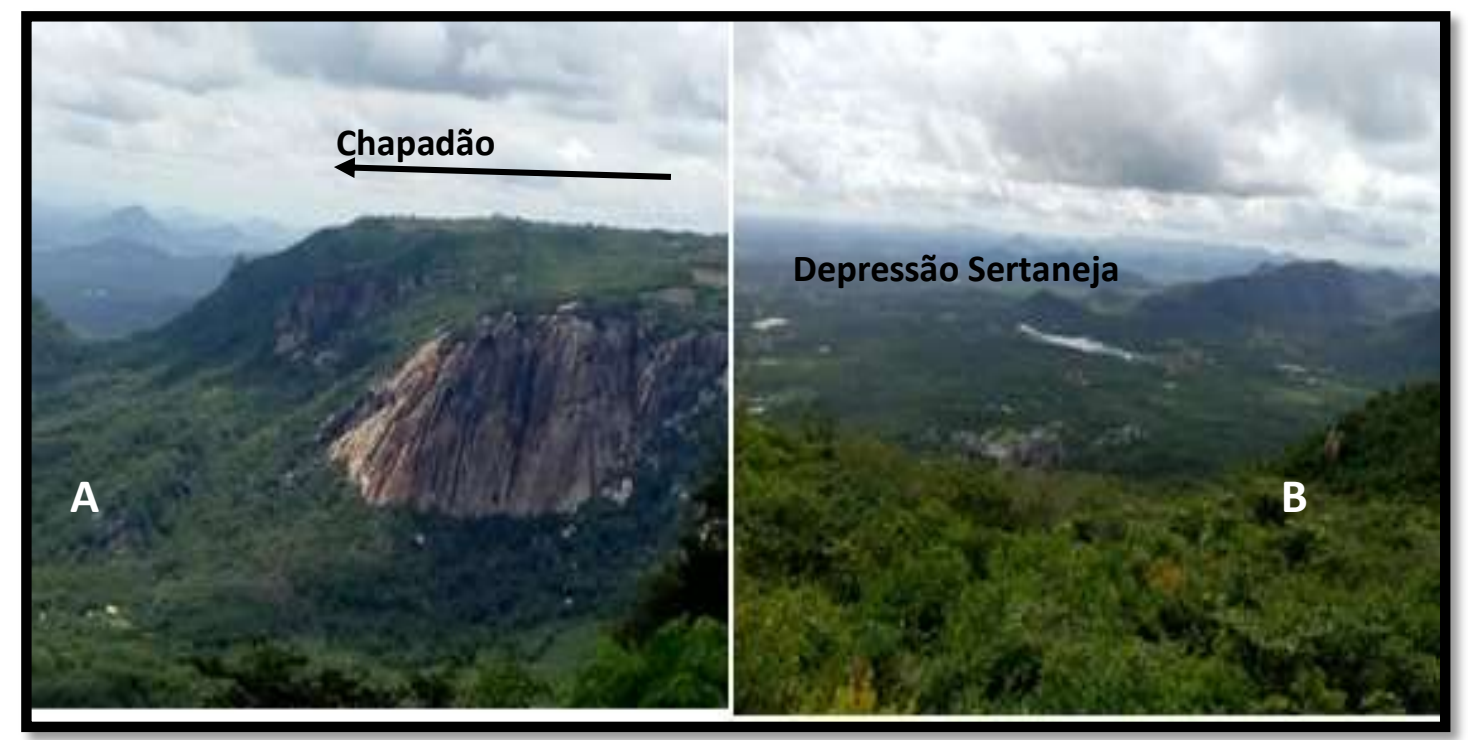

Autoria: Silva (2017).

A formação Serra do Martins congrega arenitos conglomeráticos com seixos de quartzo, arredondados, sustentados por uma matriz arenosa muito grossa a grânulos, de cor castanha (Serras de Portalegre e Martins) e creme (Serra de Santana). Também são observados arenitos formados por clastos e argilo-siltosos (COMPANHIA DE PESQUISA DE RECURSOS MINERAIS, 2006). A granulométrica da formação Serra dos Martins influencia a capacidade de infiltração da água. Por ser de base arenítica, facilita o poder de acúmulo de águas subterrâneas.

O relevo das áreas examinadas está descrito como platôs residuais do Cenozoico, que constitui um relevo plano, com restos de capeamento sedimentar elevados, facilmente 
identificados pelo aspecto retilíneo dos topos das serras. São definidos como testemunhos de antigas superficiais de erosão que ocorrem em várias partes do Nordeste oriental brasileiro, sobre as áreas cristalinas. Apresentam-se em forma de mesetas e mesas, cujas encostas possuem forte declividade e erosão severa (BARROS, 1998).

Figura 2 - Localização da Serra do Martins, no município de Martins

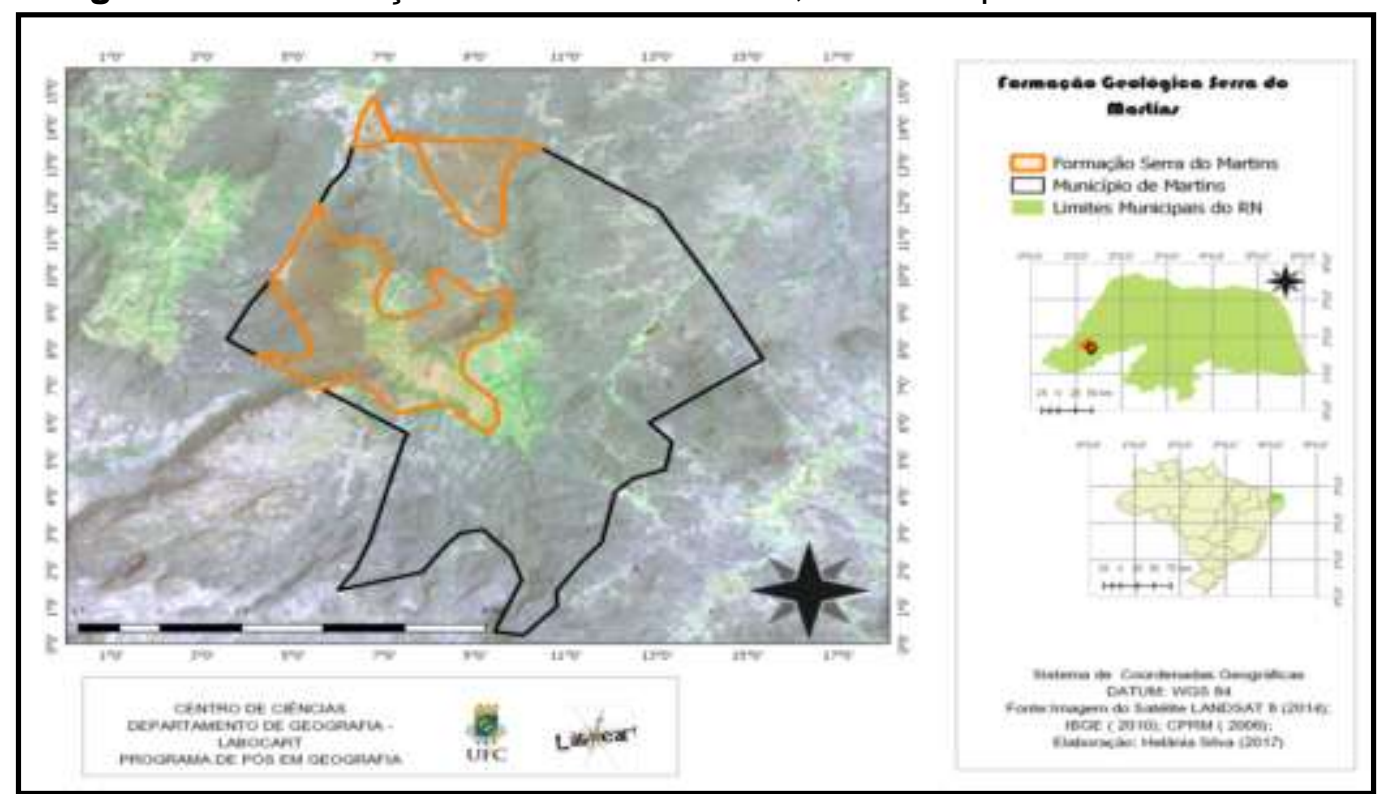

Fontes: INPE (2014); IBGE (2010) e CPRM (2006). Elaboração: Silva (2017).

\section{METODOLOLOGIA}

Nossa pesquisa se iniciou com visitas a campo na Serra de Martins (RN), cuja duração foi de uma semana ( $1^{\text {a }}$ visita em março de 2017 ) e dois dias na segunda ( $2^{\underline{a}}$ visita em maio de 2017). Posteriormente, ocorreu a aplicação dos questionários (entre os dias 16 de janeiro de 2019 até 16 de fevereiro de 2019) (Figura 3). Realizou-se também uma revisão bibliográfica sobre os temas da pesquisa: justiça ambiental; ecologia política; serviços ecossistêmicos; e segurança hídrica domiciliar.

1 visita: Foi realizada a coleta de dados primários e o registro fotográfico, o que incluiu um conhecimento da dinâmica da cidade, envolvendo conversas com setores públicos responsáveis pela gestão das águas na Serra. Visitou-se a Prefeitura; a Secretaria de Saúde; a secretaria de Agricultura; de Saneamento e obras públicas, e a Companhia de Água e Esgoto do RN (CAERN), e ainda alguns moradores de bairros centrais, com o intuito de entender quais seriam os maiores questionamentos da população quanto à distribuição hídrica e o conhecimento sobre a importância das águas subterrâneas.

2 visita: Com o apoio de um moto táxi local, conhecedor da região (atuou como um guia para essas áreas mais distantes), nossa visita foi direcionada às áreas rurais no 
município. Visitaram-se, inicialmente, quatro comunidades (Salva Vidas, Chapéu, Estaleiro e Nogueiras) abaixo da Serra. Observou-se que as comunidades são mais isoladas e que algumas já tiveram poços e açudes, mas eles estavam secos (consequência da longa estiagem). Além disso, todas possuem cisternas do Governo Federal, acumulando suas águas em épocas de chuva ou guardando a demanda ofertada pela "Operação Carro-pipa" do Exército. Como essa visita foi apenas um primeiro reconhecimento das comunidades, não envolveu a aplicação dos questionários sobre segurança hídrica domiciliar.

3 visita: Ocorreu no início do ano de 2019, com objetivo de aplicar os questionários (num total de 332), conforme dados do IBGE (2010). Para tanto, montou-se uma equipe de cinco pesquisadores divididos por bairros e áreas rurais, treinados para captar a percepção das pessoas no tocante a segurança hídrica. Eles foram identificados com crachá da pesquisa e utilizaram o aplicativo SW Maps (ferramenta de mapeamento móvel) para coletar os pontos.

Figura 3 - Etapas de investigação

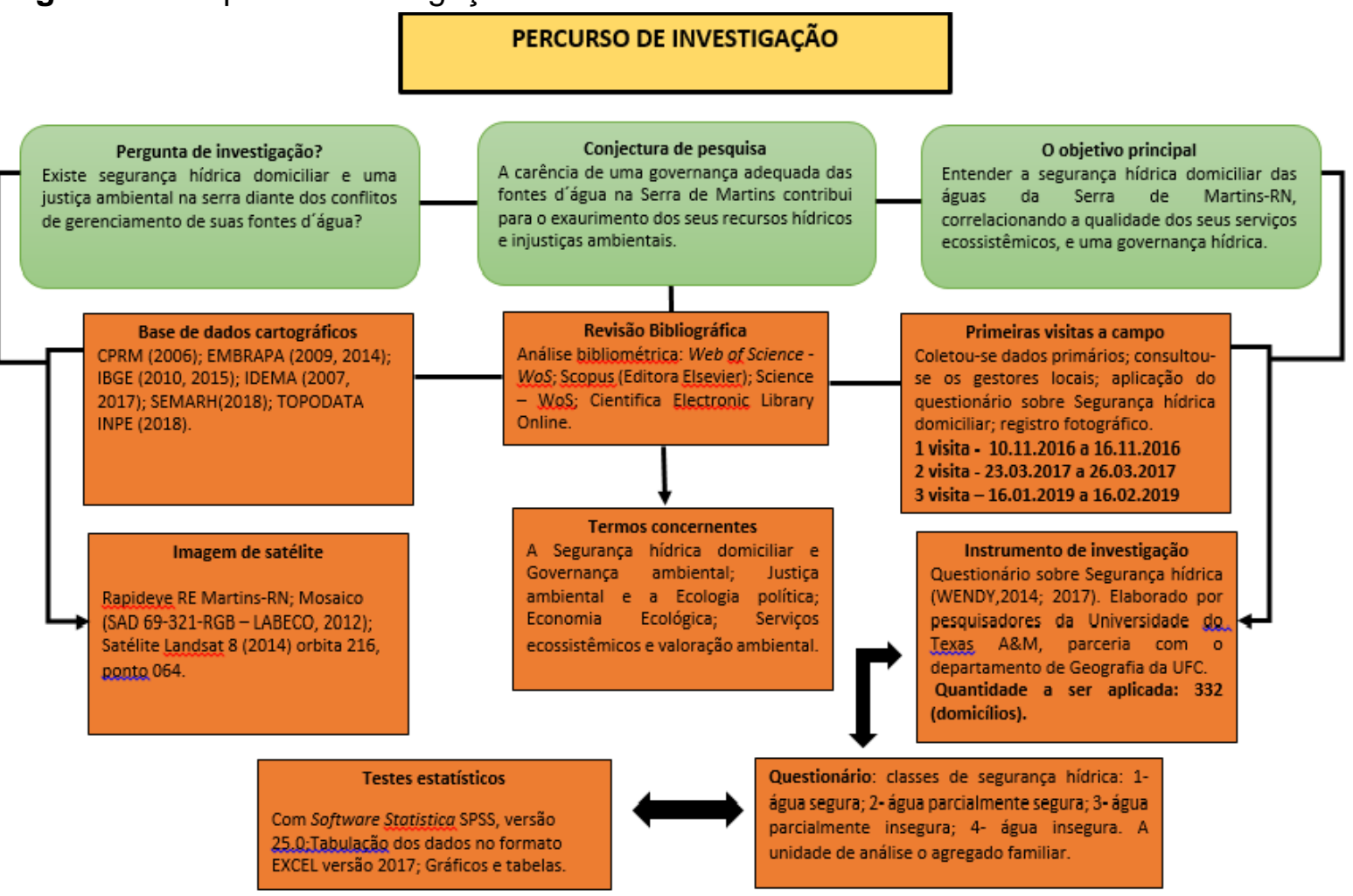

Autoria: Silva (2018).

\section{A JUSTIÇA AMBIENTAL E A ECOLOGIA POLÍTICA}

A origem da expressão justiça ambiental remonta aos movimentos sociais norteamericanos que, a partir da década de 1960, passaram a reivindicar direitos civis às 
populações afrodescendentes existentes nos EUA, bem como a protestar contra a exposição humana à contaminação tóxica de origem industrial. Dois casos foram marcantes nesse processo: o primeiro é o da poluição do Love Canal, em 1953, prejudicada por um grande aterro de lixo químico e bélico. Os moradores, a partir da exposição aos impactos, se manifestaram e criaram o movimento Love Canal em 1978, reivindicando a retirada do lixão. E o segundo movimento de destaque ocorreu em 1982, com o caso da comunidade de afroamericanos pobres da cidade de Afton, condado de Warren Country, no Estado da Carolina do Norte, quando expostos aos resíduos de policlorobifenilos (PCB). O movimento elevou a justiça ambiental à condição de questão central na luta pelos direitos civis (ACSELRAD; MELLO; BEZERRA, 2009).

Mesmo após anos de luta, os casos de injustiça ambiental no mundo perduram. Segundo um artigo de 2017, intitulado "Justiça ambiental na América", do Jornal The Guardian (MILMAN, 2017) "[...] as pessoas negras, latinas e desfavorecidas têm sido afetadas desproporcionalmente por toxinas de plantas industriais, automóveis, condições de moradia perigosas e outras fontes". Além disso, líderes políticos, acadêmicos e ativistas falam de uma urgência em torno da luta pela justiça ambiental, já que a administração de Donald Trump remove as regras projetadas para proteger o ar e a água limpa.

Para Bullard (1993), justiça ambiental é a condição de existência social configurada através do tratamento justo e do desenvolvimento significativo de todas as pessoas (independentemente de sua raça, cor ou renda), no que diz respeito à elaboração, ao desenvolvimento e à aplicação de políticas, leis e ações ambientais.

A noção de justiça ambiental implica, pois, o direito a um meio ambiente seguro, sadio e produtivo para todos, onde o meio ambiente é considerado em sua totalidade, incluindo, suas dimensões ecológicas, físicas, construídas, sociais políticas, estéticas e econômicas (ACSELRAD; MELLO; BEZERRA, 2009, p. 17).

A reivindicação por justiça ambiental em países pobres é ainda mais desafiadora, uma vez que as classes menos privilegiadas territorialmente, culturalmente e socialmente são as mais atingidas pelas problemáticas ambientais. Isso acontece porque os problemas ambientais gerados por uma sociedade do consumo imediato e descarte fácil refletem diretamente nas áreas de riscos, nos redutos de população segregada, obrigadas a conviverem com a falta de saneamento básico, de água potável, de moradia digna e de acesso à educação, segurança, saúde e lazer.

$E$, certamente, essa injustiça é ainda mais sólida nos países subdesenvolvidos ou "ditos em desenvolvimento", marcados por uma industrialização tardia, precária e exploratória de suas matérias-primas. Isso envolve um deslocamento de transnacionais dos 
países ricos para terras fartas de fatores locacionais, elementos estratégicos para atrair essas indústrias que, na maioria, mais causam injustiças às nações pobres do que promovem a geração de emprego, de renda e melhorias econômicas.

Martinez-Alier (2001) ressalta, porém, que existe uma diferença entre o movimento por justiça ambiental norte-americano e os movimentos por justiça ambiental "terceiromundistas". A diferença é bastante significativa: enquanto o movimento por justiça ambiental norte-americano se notabiliza por lutas em favor de grupos minoritários e contra o racismo ambiental nos EUA, os movimentos por justiça ambiental de fora dos EUA "[...] lutam contra impactos ambientais que ameaçam os pobres, que constituem a ampla maioria da população em muitos países".

Acselrad, Herculano e Pádua (2004) destacam que no Brasil tanto a injustiça social quanto a discriminação de parcelas da população são percebidas no modelo elitista de apropriação do espaço territorial e dos recursos naturais da nação, bem como na exposição desigual da população brasileira à poluição e aos custos ambientais do desenvolvimento.

No Brasil, é um fator histórico a exploração de suas florestas, solos, minérios e, principalmente, corpos d'água. As águas brasileiras tornam-se parte de um capital extra, comercializado injustamente, pois muitas empresas já se instalam recebendo como garantia uma demanda descontrolada das fontes d'água, o que impacta essas fontes, gerando a desigualdade no seu uso. Certamente, o território acaba sendo desterritorializado por multinacionais e por uma governança nada ecológica.

A título de exemplo, temos a tragédia de Brumadinho, ocorrida no Estado de Minas Gerais, no dia 25 de janeiro de 2019, cuja barragem de rejeito 1 da mineradora Vale S.A. (multinacional) se rompeu, causando mais de 200 mortes e irreversíveis danos socioeconômicos e ambientais. A lama tomou conta do povoado, das instalações da empresa e do Rio Paraopeba (que banha Minas Gerais). Essa terra era sobrevivência de comunidades pobres e já vulneráveis aos impactos da mineração. Por isso, citamos esse caso desastroso de injustiça ambiental para com o povoado e todos os envolvidos, pois nenhuma indenização compensará os dados ambientais, humanitários e paisagísticos daquela área.

Enquanto isso, a prioridade ao lucro privado pode ser atestada pelo avanço do agronegócio e da mineração sobre novos territórios, colocando em xeque a existência de comunidades tradicionais. Em plena crise hídrica, na discussão de sua gravidade, nenhuma atenção é dada à responsabilidade dos setores mineral e agropecuário, com sua demanda intensiva por água, na configuração do quadro de escassez (REDE BRASILEIRA DE JUSTIÇA AMBIENTAL, 2015).

A justiça ambiental no Brasil é claramente falha e mantém uma constrangedora história de exploração dos recursos naturais: roubo da biodiversidade, destruição de 
florestas e matas nativas, poluição das águas superficiais e subterrâneas, exportação do seu patrimônio genético, destruição dos valores enraizados em povos tradicionais e, acima de tudo, injustiça com aqueles que tentam reivindicar os princípios básicos assegurados pela Constituição Federal, Art. 225, ao citar que todos têm direito ao meio ambiente ecologicamente equilibrado. (BRASIL, 1988).

Cabe, assim, uma indagação: quais classes brasileiras realmente usufruem de um meio ambiente equilibrado, longe de poluição e contaminação, usufruindo, verdadeiramente, de um patrimônio natural preservado? Indo além: e quais ações ambientais o poder público direciona para o bem da coletividade?

É notório que as classes brasileiras que usufruem de um meio ambiente longe da contaminação são as que moram em redutos protegidos, loteamentos planejados, uma paisagem construída pelo capital. Classes que desfrutam de uma melhor infraestrutura nos seus locais de moradia compram os melhores terrenos do sítio urbano e, muitas vezes, não percebem a degradação ao redor, pois não são atingidos diretamente pelos impactos ambientais.

A luta por justiça ambiental no Brasil é representada por classes sociais excluídas dessa falsa integridade territorial e ecológica. e são as mesmas que sentem no dia a dia as dificuldades, convivendo com um meio ambiente degradado. As que estão em áreas de risco (sejam essas da mineração ou próximas a rios poluídos e encostas), lutando por suas terras antes produtivas, são as mesmas que tentam revitalizar seus solos férteis, suas matas, suas fontes de água potável e aproveitar a função social da terra.

Mas nessas formulações os pobres estão como seres passivos, pois são os mais atingidos pela degradação ambiental. Na prática, não ocorrem muitas ações ambientais que visem um benefício coletivo. As cidades vão sendo construídas desordenadamente, e a falta de planejamento ambiental é notória. A esperança surge timidamente em grupos isolados que lutam por um meio ambiente para todos, como: ONGs, grupos ambientais e iniciativas da comunidade. Mesmo assim, são poucos projetos voltados à conservação.

No Brasil, o maior fortalecimento da Rede por Justiça Ambiental ocorreu após o Colóquio Internacional sobre Justiça Ambiental, Trabalho e Cidadania, em 2001, sendo um marco da sistematização a publicação da coleção sobre Sindicalismo e Justiça ambiental, em 2000, pela Central Única dos Trabalhadores (CUT - em parceria com a RJ, IBASE, IPPUR-UFRJ).

Yo creo que de las protestas, de las resistencias es de donde nacerán las alternativas. Éstas no van a nacer de ningún partido político que determine la línea correcta. También ocupamos más espacio, destruyendo ecosistemas y arrinconando otras especies. Por tanto aumentan los conflictos ecológico-distributivos. La Deuda Ecológica se puede expresar en 
dinero pero tiene también aspectos morales que no quedan recogidos en una valoración monetaria (MARTINEZ-ALIER, 2005, p. 3).

Leff (2006, p. 4) afirma que "A la ecología política le conciernen no sólo los conflictos de distribución ecológica, sino el explorar con nueva luz las relaciones de poder que se entretejen entre los mundos de vida de las personas y el mundo globalizado", sendo comum tanto a apropriação de recursos vitais em comunidades interioranas e tradicionais (como a água limpa, que deveria chegar as suas residências) quanto a de recursos naturais de alto valor no mercado internacional.

A concentração dos benefícios do desenvolvimento nas mãos de poucos, bem como a destinação desproporcional dos riscos ambientais para os mais pobres e para os grupos étnicos mais despossuídos, permanece ausente da pauta de discussão dos governos e das grandes corporações (ACSELRAD; MELLO; BEZERRA, 2009).

Para Acselrad, Herculano e Pádua (2004), no caso do Brasil, o potencial político do movimento pela justiça ambiental é enorme. O país é injusto em termo de distribuição de renda e acesso aos recursos naturais. Sua elite governante tem sido insensível, defendendo de todas as formas os seus interesses e lucros imediatos, sendo omissos e negligentes no atendimento às necessidades das classes populares. Não há como chamar de progresso e desenvolvimento o processo de empobrecimento e envenenamento dos que já são pobres. Não é justo que os lucros das grandes empresas se façam à custa da miséria da maioria.

Segundo Acselrad, Mello e Bezerra (2009, p. 123), “[...] o processo da territorialidade capitalista brasileira é o de privatização do uso do meio ambiente comum, mais especificamente, do ar e das águas de que dependem todos os grupos humanos". Assim, os conflitos socioambientais se dão no uso desenfreado dos serviços ecossistêmicos, em que a busca por um progresso produtivo interfere diretamente nas funções ecológicas: desequilibram os ecossistemas, alteram a entrada e a saída de energia e todo o ciclo biogeoquímico da natureza.

Os serviços ecossistêmicos são apropriados enquanto "serviços" para o homem, sendo usados em moldes de sobrevivência não racionais. São impactados pelas atividades econômicas, pautadas em extração ilimitada e não reposição dos estoques essenciais à natureza e às gerações futuras.

\section{OS SERVIÇOS ECOSSISTÊMICOS: O ENTENDIMENTO CONCEITUAL E A URGÊNCIA EM SUA CONSERVAÇÃO}

De acordo com May (2010), o entendimento da dinâmica dos ecossistemas requer um esforço de mapeamento das chamadas funções ecossistêmicas, as quais podem ser 
definidas como as constantes interações existentes entre o elementos estruturais de um ecossistema - incluindo transferências de energia, ciclagem de nutrientes, regulação de gás, regulação climática e do ciclo da água, funções que se traduzem em serviços ecossistêmicos à proporção que beneficiam as sociedades humanas.

Para Millennium Ecosystem Assessment (2005), os serviços dos ecossistemas são os benefícios que as pessoas recebem desse. Eles incluem: os serviços de provisão (como alimento e água); de regulação de enchentes, de secas, de doenças e da degradação dos solos; de suporte, como a formação dos solos e os ciclos de nutrientes; e, por fim, os serviços culturais, de valor espiritual/religioso e outros benefícios não materiais.

Para Whately e Hercowitz (2008, p. 15), “[...] o termo 'serviços ambientais' é definido de diversas formas na literatura especializada, podendo também ser identificado como serviços ecossistêmicos ou serviços ecológicos”. E, conforme May (2010), há certa confusão na literatura entre os conceitos de "serviços ecossistêmicos" e "serviços ambientais". Serviços ecossistêmicos foram definidos por Daily et al. (1997) como os serviços prestados pelos ecossistemas naturais e pelas espécies que o compõem, na sustentação e preenchimento das condições para a permanência da vida humana na terra. Essas capacidades são classificadas como funções dos ecossistemas. Já os serviços ambientais são mais relacionados aos resultados desses processos ou, ainda, quando se deseja atrelar as ações antrópicas associadas à restauração e manutenção dos serviços ecossistêmicos (enquanto as funções dos ecossistemas são mais associadas com a sua origem).

Na relação de apropriação dos serviços ecossistêmicos, a ideia de uma preservação intrínseca à sua oferta futura é esquecida. Não teremos corpos d'água saudáveis, ou águas subterrâneas acumuladas, se não cultivarmos florestas, se não conservarmos os solos ou se continuarmos poluindo e contaminando esses serviços. "Em diversos recantos do planeta, a água é um privilégio da elite, enquanto a maioria pobre sofre com sua escassez. Isso só revela mais uma faceta das inúmeras injustiças ambientais que assolam o planeta." (RAMMÊ, 2012, p. 42).

O Relatório da Millennium Ecosystem Assessment (2005) traz alguns questionamentos interessantes: quais são as condições atuais e as tendências dos ecossistemas, dos serviços ecossistêmicos e do bem-estar humano? A MEA não se propôs a gerar conhecimentos primários, mas a sistematizar, avaliar, interpretar, integrar e divulgar as informações existentes de forma útil e apropriável para os sujeitos sociais tomadores de decisão e a sociedade.

As mudanças ocorridas nos ecossistemas contribuíram com ganhos finais substanciais para o bem-estar humano e o desenvolvimento econômico. Porém, esses ganhos foram obtidos a um custo crescente, baseado na perda do patrimônio natural ou da riqueza de um país. 
No intuito de reverter esse quadro, segundo o relatório da Millennium Ecosystem Assessment (2005), as ações devem ser significativas, como: investimentos em políticas públicas e redução da pobreza; eliminação de barreiras comerciais e subsídios abusivos; investimentos em novas tecnologias e pagamentos por serviços ambientais; mudanças nos padrões de consumo; delegação de poderes; e incorporação de valores não comercializáveis.

De acordo com Tito e Ortiz (2013), inicialmente, vale conceituar Pagamentos por Serviços Ambientais (PSA) no contexto da modalidade água. Segundo a Agência Nacional de Águas (2008, p. 15), eles são "[...] transferências financeiras de beneficiários de serviços ambientais para os que, devido a práticas que conservam a natureza, fornecem esses serviços ambientais". Os beneficiários são todos os agentes, privados ou públicos, que são favorecidos pelos serviços ambientais oriundos de práticas que conservam a natureza. Para Motta (2006, p. 13):

Os métodos de valoração econômica do meio ambiente são parte do arcabouço teórico da microeconomia do bem-estar e são necessários na determinação dos custos e benefícios sociais quando as decisões de investimentos públicos afetam o consumo da população (seu conforto e segurança).

Em nosso país, a prática de PSA já ocorre em alguns municípios, como o projeto Conservador das Águas. Segundo Jardim e Bursztyn (2015), o caso de Extrema, em Minas Gerais, teve destaque por ser a primeira iniciativa municipal a realizar pagamentos para proprietários rurais em troca da garantia do fornecimento de serviços ambientais, visando a melhoria dos recursos hídricos. Para Guedes e Seehusen (2011, p. 12), "[...] no Brasil, os esquemas de PSAs se multiplicam rapidamente, sejam eles privados (coordenados e financiados com recursos de empresas e ONGs) ou públicos, impulsionados e financiados por governos em seus diversos níveis".

\section{SEGURANÇA HÍDRICA DOMICILIAR E OS SERVIÇOS ECOSSISTÊMICOS NA SERRA DE MARTINS - RN}

A distribuição e a qualidade da água são diferenciadas nos países desenvolvidos e nas nações pobres do globo. Existe uma verdadeira relação de injustiça ambiental quando se trata da água. Ocorrem processos injustos de apropriação desse bem comum por classes privadas, ou poluição dos corpos d'água pelas atividades produtivas, que exploram as fontes limpas, destroem as matas ciliares e de encostas e ainda renegam a sua conservação. 
Como exemplo, temos a explotação das águas subterrâneas acima de sua capacidade de recarga.

Martinez-Alier (2007, p. 113) escreve que "[...] os determinantes da distribuição ecológica são naturais, como o clima, o solo. No entanto, são claramente sociais, econômicos, políticos e tecnológicos". Os conflitos ecológicos distributivos trazem a relação do meio ambiente com a economia e as problemáticas sociais. Já os conflitos distributivos envolvendo a água perpassam barreiras geográficas, políticas e ambientais, revelando nações que disputam o acesso a esse bem, confrontando diferentes atores sociais nessa partilha.

Para Jepson et al. (2017, p. 3), “[...] a segurança da água é dada pela capacidade de entendê-la necessariamente como parte de um processo hidrossocial que é simultaneamente material, discursivo e simbólico". Ela tem um valor diferente, não apenas material ou social, mas envolvendo escalas coletivas na interação. Dessa maneira, concentrando-se na abordagem de sua política e dimensões culturais, a segurança hídrica permeia um amplo campo de investigação.

A distribuição da água na Serra do Martins envolve atores de uma gestão municipal e políticas governamentais em parcerias imediatistas, para assim conter a falta d'água intensificada pelo ciclo das secas (seis anos na região semiárida). Isso interferiu no acúmulo das águas subterrâneas, numa estrutura sedimentar e na recarga dos corpos d'água superficiais, como o açude da cidade vizinha de Lucrécia - RN. Este açude é a fonte d'água captada pela (CAERN) Companhia de Águas e Esgotos do Rio Grande do Norte, para abastecimento do município de Lucrécia e Martins em situação de não estiagem.

A Serra do Martins, mesmo predisposta a serviços ecossistêmicos essenciais à qualidade de vida da população e à manutenção da quantidade das águas subterrâneas, demonstra, através da nossa pesquisa, um conflituoso cenário no acesso e na distribuição desse recurso hídrico, sendo problemática a sua obtenção.

Os representantes da governança hídrica em Martins são a (CAERN) e a Prefeitura, que contabilizam em torno de 30 poços ativos e com água de boa qualidade. Entretanto, segundo dados de 2017 da (SEMARH) secretaria de Meio Ambiente e Recursos Hídricos, são cerca de 60 poços (Figura 4). Há também o Exército com a operação Carro-pipa (Parceria Exército, Governo Estadual e Prefeitura). Além disso, existe o sistema de distribuição realizado pelos próprios moradores, que retiram água dos poços públicos e vendem para aqueles cujas dificuldades no acesso são maiores (privatizando assim um bem público e de uso coletivo). Foram relatados casos em que a população usufruía de torneiras públicas, instaladas por toda a cidade, porém alguns retiravam água em excesso, gerando conflitos no seu uso. Após denúncias, o Ministério Público local encaminhou o desligamento de todas as torneiras. (RIO GRANDE DO NORTE, 2017). 


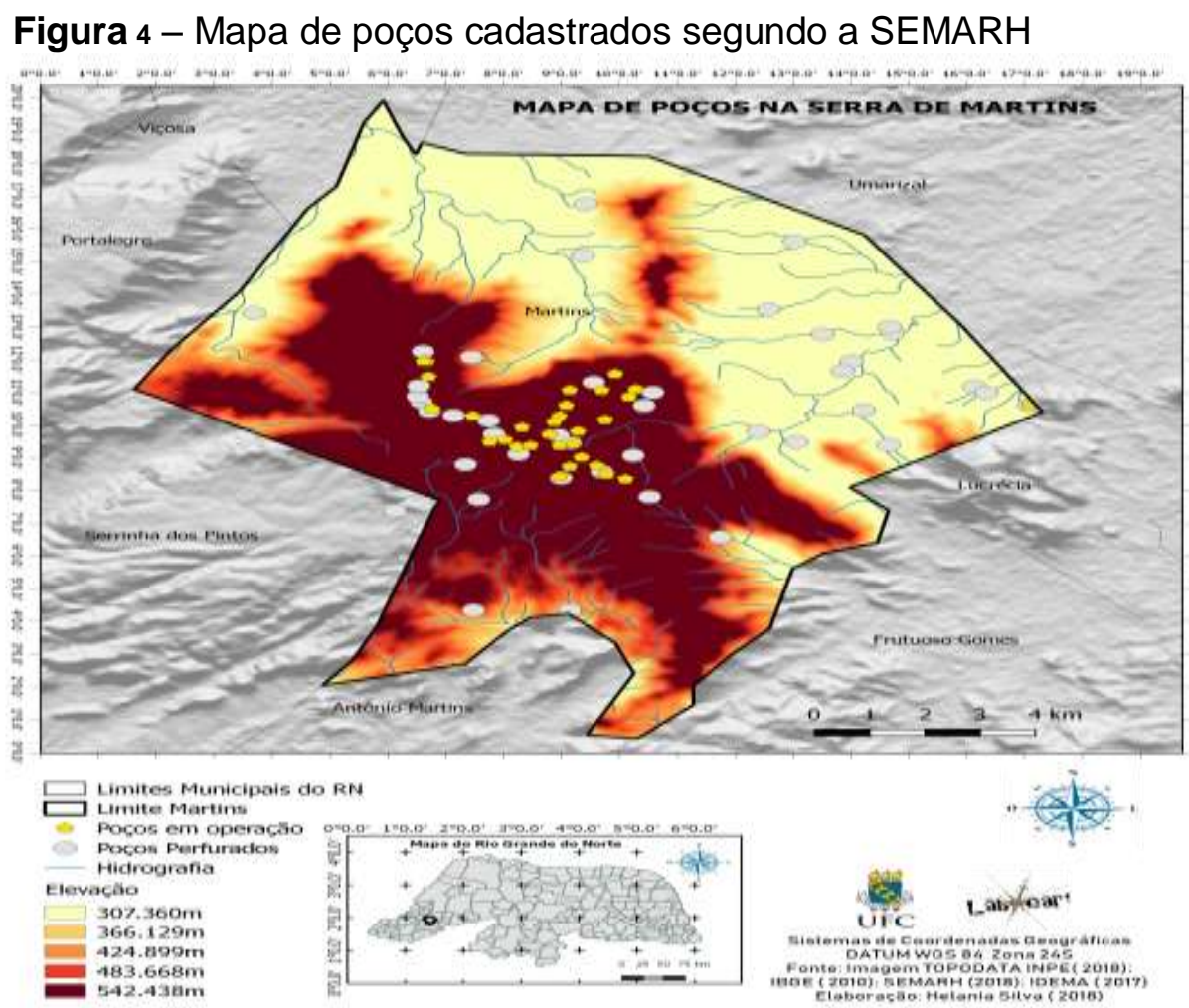

Fontes: INPE (2014); IBGE (2010); SEMARH (2017). Elaboração: Silva (2017).

Já no meio rural, os moradores se utilizam das cisternas, vindas de projetos federais como o "Água para Todos", com a instalação dessas para acumularem água em épocas difíceis (água de $1^{\circ}$ e $2^{\circ}$ uso). Constata-se que mesmo com toda a atuação dos muitos gestores, os conflitos distributivos hídricos são enraizados e, por isso, não percebidos pela população, que não compreende que a água não chega para todos de forma saudável e com facilidade no acesso. A comunidade se considera satisfeita com situações pontuais de distribuição da água (por exemplo, os carros-pipas que abastecem a cada 10 ou 15 dias). Deste modo, a comunidade é influenciada ainda pelas políticas locais, as quais interferem no seu grau de reivindicação. Dependendo do prefeito ou dos grupos que estão no poder, ocorre a maior ou menor percepção da situação de insegurança hídrica pela população.

Essas relações revelam a concentração de poder e capital, bem como a injustiça ambiental com os mais vulneráveis, demonstrando que os programas do Governo do Estado quanto à distribuição de água ainda são questionáveis. O Governo caminha para implantação de barreiros e perfuração de poços para regiões de maior deficiência hídrica, mas será que realmente esses benefícios chegarão aos mais desfavorecidos? Será que os apadrinhamentos políticos não influenciarão na logística de instalação daqueles? Afinal, qual fazendeiro não deseja um poço gratuito em sua propriedade? 
Observou-se que os conflitos locais não são tão diferentes dos conflitos globais: a água não atinge padrões de qualidade para todos, não chega aos que realmente necessitam; mas é farta para as elites, aquelas que podem perfurar seus poços, na maioria sem outorga de uso d'água e sem a devida preocupação com a sua explotação intensiva. A própria água da CAERN não chega regularmente aos bairros mais distantes, coincidentemente os mais pobres da cidade - fato não observado nos bairros centrais, de população com maior poder aquisitivo. A gestão não se atenta à troca de encanamentos ou vazamentos pontuais, acarretando desperdício. E os que "vendem" essa água a transportam de forma não adequada, muitas vezes adaptando vasilhames enferrujados ou de antigo uso de agrotóxicos (Figura 5).

Figura 5 - Moto pipa adaptado para o transporte e venda d'água na Serra

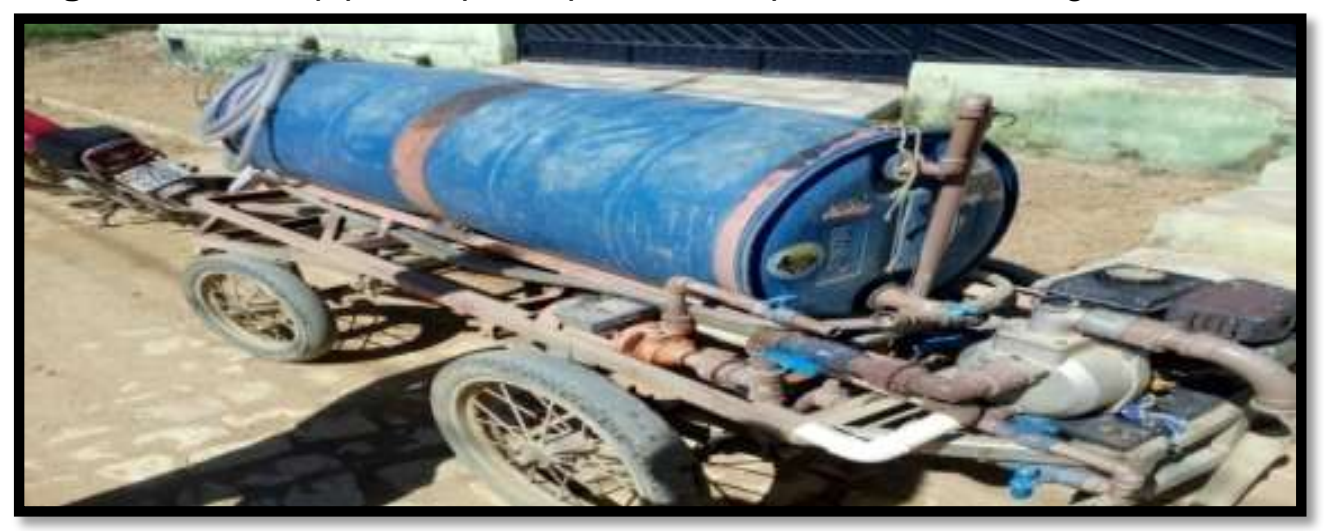

Autoria: Silva (2017).

Nesse processo, gestores e parte da comunidade não percebem a riqueza hídrica proveniente de suas águas subterrâneas. Falta percepção ambiental quanto à preservação desse recurso e um maior entendimento do que são os serviços ecossistêmicos ofertados pela natureza (e como esses podem melhorar a vida local). Como um município seria inseguro hidricamente se o mesmo possui fontes ricas de abastecimento? E, mesmo a Serra do Martins possuindo ricas fontes subterrâneas, ocorrem dificuldades por parte da população para a sua captação e distribuição coletiva. Por isso, é comum o discurso de problemas de saúde relacionados à elevada quantidade de minerais na água, o que gera medo (principalmente em idosos), fazendo com que alguns prefiram comprar água mineral engarrafada para beber. Soma-se a isso a falta de uma distribuição adequada para levar essa água até os bairros mais distantes ou até mesmo às comunidades rurais. Pois não adianta água em oferta quando culturalmente existe um medo de contaminação dela, ou quando muitos não conseguem se deslocar para buscá-la, por falta de transporte ou de vasilhames suficientes. 
São nas serras úmidas sedimentares que as águas subterrâneas surgem na superfície originando as fontes hídricas mais acessíveis e de relevância primordial para a sobrevivência da população. Os municípios Serranos de Martins e Portalegre possuem algumas dessas reservas seguras de água que precisam ser monitoradas. Foram encontradas ao todo nove nascentes, cuja necessidade de preservação é urgente (NERES, 2014). Essas reservas possibilitam o uso pela população e estabelecem uma importância ecológica para manter o equilíbrio do ecossistema.

Não há como dissociar a conservação dos recursos hídricos subterrâneos e superficiais dos processos de manejo adequado dos solos, da proteção das margens dos rios e do controle na exploração das águas, uma vez que a sustentabilidade daqueles depende diretamente desses fatores. Discutir segurança hídrica domiciliar é enxergar que os conflitos de acesso e conservação da água vão além da sua demanda. O seu exaurimento não é consequência somente de sua oferta, mas sim de uma governança insatisfatória dos corpos hídricos e de uma apropriação injusta no que tange à preservação desses serviços ecossistêmicos essenciais.

Assim, cabe lembrar que a justiça ambiental acontece quando as comunidades tradicionais conseguem um uso e uma distribuição equitativa dos serviços ecossistêmicos; e quando as elites não se apropriarem de uma parcela maior dos benefícios da natureza, usufruindo dela a seu bel-prazer, em demandas superiores às comunidades pobres.

Certamente, não há desenvolvimento que desarticule por completo a economia, a política e os conflitos distributivos. A ecologia está na política, está na economia. E uma governança hídrica deveria considerar as injustiças locais e globais quanto ao modo de sobrevivência dos povos e como incorporar uma exploração menos impactante dos serviços ecossistêmicos.

\section{CONSIDERAÇÕES FINAIS}

Por fim, a análise entre segurança hídrica domiciliar e os serviços ecossistêmicos revela conflitos ecológicos distributivos no acesso às fontes subterrâneas, bem como demarca a falta de políticas públicas de regulação e distribuição da água para as comunidades mais afetadas pela pobreza, aquelas mais distantes do centro e as comunidades rurais. A água é escassa, mesmo num ambiente natural de predisposição hídrica. Fato ocasionado pela má governança local. As fontes de abastecimento são diferentes nas residências: dependendo da localidade e do poder aquisitivo, utiliza-se com maior ou menor frequência os poços públicos ou privados. E tornou-se comum entre os moradores o medo de consumir água com alto teor de minerais, o que os leva a comprar água engarrafada toda semana. Além disso, nas áreas rurais abaixo da serra, os açudes 
públicos e o pouco de água que ainda restava foi a sustentação de muitas famílias no período de escassez, ajudando a matar a sede dos animais e para o uso das atividades domésticas. Portanto, a pesquisa evidencia uma insegurança hídrica domiciliar na Serra do Martins.

A partir desta investigação, notou-se que há sérios impactos no uso dos serviços ecossistêmicos de provisão (água), por consequência de: crescimento urbano desordenado; ocupação e poluição das áreas de nascentes; retirada da mata nativa e das encostas; instalação de poços sem controle; e alteração na oferta d'água por condições naturais (longo período de estiagem no Nordeste). Portanto, tais aspectos conferem práticas de injustiça ambiental, pois a oferta d'água não atende a todos de forma igualitária (a população melhor localizada sofre menos com esses conflitos - alguns nem ao menos os percebem). A própria água da CAERN chega com maior frequência e o acesso aos poços públicos é facilitado.

Mesmo com os diferentes atores na gestão das águas na Serra do Martins, percebeu-se que não há uma integração no gerenciamento como um todo. A governança hídrica é ineficiente e não inclui políticas públicas sistêmicas e voltadas à conservação dessa água subterrânea, numa Serra, no meio do semiárido Nordestino, uma rica paisagem de exceção ou enclave úmido do sertão.

Consequentemente, o que se espera são direcionamentos mais interdisciplinares e justos quanto à segurança hídrica domiciliar, incluindo uma segurança hidrossocial: uma distribuição menos desigual e projetos voltados à conservação das funções dos ecossistemas (iniciativas como o reconhecimento desses serviços e o Pagamento por Serviços Ambientais a moradores que preservarem as nascentes e as águas subterrâneas), assim garantindo a populações novas alternativas de sobrevivência nessa Serra, o que assegura os serviços ecossistêmicos para gerações atuais e futuras, proporcionando água em demanda e com qualidade para as diversas atividades humanas.

\section{REFERÊNCIAS}

ACSELRAD, H.; HERCULANO, S.; PÁDUA, J. A. Justiça ambiental e cidadania. Rio de Janeiro: Relume Dumará, 2004.

ACSELRAD, H.; MELLO, C. C. do A.; BEZERRA, G. das N. O que é justiça ambiental. Rio de Janeiro: Garamond, 2009.

AGÊNCIA NACIONAL DE ÁGUAS - ANA. Programa produtor de água. Brasília, DF:

Superintendência de Usos Múltiplos, 2008. Disponível em:

http://produtordeagua.ana.gov.br/Portals/0/DocsDNN6/documentos/Folder\%20-

\%20Programa\%20Produtor\%20de\%20\%C3\%81gua.pdf. Acesso em: 9 dez. 2018. 
BARROS, S. D. S. Aspectos morfo-tectônicos dos platôs de Portalegre, Martins e Santana - RN. 1998. Dissertação (Mestrado em Geodinâmica e Geofísica) - Universidade Federal do Rio Grande do Norte, RN, Natal, 1998.

BRASIL. [Constituição (1988)]. Constituição da República Federativa do Brasil de 1988. Brasília, DF: Sendo Federal, 1988. Disponível em:

https://www2.senado.leg.br/bdsf/handle/id/518231. Acesso em: 10 dez. 2018.

BULLARD, R. Enfrentando o racismo ambiental: vozes das bases. Boston: South End Press, 1993.

COMPANHIA DE PESQUISA DE RECURSOS MINERAIS - CPRM. Serviço Geológico do Brasil. Geologia e recursos minerais do Estado do Rio Grande do Norte. Recife: CPRM, 2006.

COOK, C.; BAKKER, K. Water security: debating an emerging paradigm. Global

Environmental Change, Guildford, GB, v. 22, n. 1, p. 94-102, Feb. 2012.

DAILY, G. C.; POSTEL, S.; BAWA, K.; KAUFMAN, L. Nature's services: societal dependence on natural ecosystems. Washington, DC: Island, 1997.

GLOBAL WATER PARTNERSHIP. Towards water security: a framework for action.

Stockholm, SW: Global Water Partnership, 2000. Disponível em: https://www.gwp.org/. Acesso em: 9. dez. 2018.

GUEDES, F. B.; SEEHUSEN, S. E. Pagamentos por serviços ambientais na mata atlântica: lições aprendidas e desafios. Brasília, DF: MMA, 2011.

IBGE. Cidades. Martins, RN. 2010. Disponível em:

https://cidades.ibge.gov.br/brasil/rn/martins/panorama. Acesso em: 10 maio 2019.

INSTITUTO NACIONAL DE PESQUISAS ESPACIAIS - INPE. Divisão de Geração de Imagens. Catálogo de Imagens. LANDSAT-8. 2014. Disponível em:

http://www.dgi.inpe.br/CDSR/. Acesso em: 25 jun. 2017.

JARDIM, M. H.; BURSZTYN, M. A. Pagamento por serviços ambientais na gestão de recursos hídricos: o caso de Extrema (MG). Revista de Engenharia sanitária Ambiental, Rio de Janeiro, v. 20, n. 3. p. 353-360, jul./set. 2015.

JEPSON, W.; BUDDS, J.; EICHELBERGER, L.; HARRIS, L.; NORMAN, E.; O'REILLY, K.; PEARSON, A.; SHAH, S.; SHINN, J.; STADDON, C.; STOLER, J.; WUTICH, A.; YOUNG, S. Advancing human capabilities for water security: a relational approach. Water Security, New York, NY, v. 1, p. 46-52, Jul. 2017. ISSN 2468-3124. DOI:

https://doi.org/10.1016/j.wasec.2017.07.001. Disponível em:

https://www.sciencedirect.com/science/article/pii/S2468312417300032?via\%3Dihub. Acesso em: 20. dez. 2017.

LEFF, E. La ecología política en América Latina: un campo en construcción. In: ALIMONDA, $\mathrm{H}$. Los tormentos de la materia:. aportes para una ecología política latinoamericana.

Buenos Aires: CLACSO, 2006. p. 21-39. Disponível em:

http://biblioteca.clacso.edu.ar/clacso/gt/20101002065259/alimonda2.pdf. Acesso em: 3 dez. 2018.

MARTINEZ-ALIER, J. El ecologismo de los pobres: conflictos ambientales y lenguajes de valoración. Barcelona: Icaria Editorial, 2005. 
MARTINEZ-ALIER. J. Mining conflicts, environmental justice, and valuation. Journal of Hazardous Materials, Barcelona, n. 86, p.153-170, 2001. Disponível em:

https://kundoc.com/pdf-mining-conflicts-environmental-justice-and-valuation-.html. Acesso em: 18 dez. 2018.

MARTINEZ-ALIER. J. O ecologismo dos pobres: conflitos ambientais e linguagens de valoração. São Paulo: Contexto, 2007.

MAY, P. H. (org.). Economia do meio ambiente: teoria e prática. Rio de Janeiro: Elsevier: Campus, 2010.

MILLENNIUM ECOSYSTEM ASSESSMENT. Ecosystems and human well-being: synthesis. Washington, DC: Island Press, 2005. Disponível em:

https://www.millenniumassessment.org/documents/document.356.aspx.pdf. Acesso em: 29 dez. 2017.

MILMAN, O. Environmental justice in America: a civil rights 'emergency': justice, clean air and water in the age of Trump. The Guardian, Haywards Heath, SU, 20 nov. 2017. News. Disponível em: https://www.theguardian.com/us-news/2017/nov/20/environmental-justice-inthe-age-of-trump. Acesso em: $11 \mathrm{dez} .2017$.

MOTTA, R. S. da. Economia ambiental. Rio de Janeiro: FGV, 2006.

NERES, S. T. Nascentes da região serrana de Porto Alegre e Martins: aspectos hidrodinâmicos e macroscópicos como subsidio a conservação. 2014. Dissertação (Mestrado em Ciências naturais) - Universidade Estadual do Rio Grande do Norte, Mossoró, RN, 2014.

RAMMÊ, R. S. Da justiça ambiental aos direitos e deveres ecológicos. Conjecturas políticos-filosóficas para uma nova ordem jurídico-ecológica. Caxias do Sul, RS: EDUCS, 2012. Disponível em:

https://www.ucs.br/site/midia/arquivos/JUSTICA_AMBIENTAL_EDUCS_EBOOK.pdf. Acesso em: 11 dez. 2018.

REDE BRASILEIRA DE JUSTIÇA AMBIENTAL. Quem somos. 2015. Disponível em: http://www.justicaambiental.org.br. Acesso em: 19 dez. 2018.

RIO GRANDE DO NORTE (Estado). Secretaria de Meio Ambiente e Recursos Hídricos SEMARH. Informações sobre cadastro de poços no RN. 2017. Disponível em: http://www.semarh.rn.gov.br/. Acesso em: 20 dez. 2017.

SOUZA, M. J. N. de; OLIVEIRA, V. P. V. de. Os enclaves úmidos e sub-úmidos do semiárido do nordeste brasileiro. Mercator, Fortaleza, v. 5, n. 9, p. 85-102, nov. 2006.

TITO, M. R.; ORTIZ, R. A. Projeto apoio aos diálogos setoriais EU-Brasil. Pagamentos por serviços ambientais: desafios para estimular a demanda. Brasília, DF: MMA, 2013.

WHATELY, M.; HERCOWITZ, M. Serviços ambientais: conhecer, valorizar e cuidar: subsídios para a proteção dos mananciais de São Paulo. São Paulo: Instituto Socioambiental, 2008.

Recebido: fevereiro de 2019. Aceito: junho de 2019. 